\title{
PRIMARY AND SECONDARY REINFORCEMENTS IN REINFORCED CONCRETE CORBELS
}

\author{
Mehdi REZAEI, Siti Aminah OSMAN, Nandivaram E. SHANMUGAM \\ Department of Civil \& Structural Engineering, The National University of Malaysia (UKM), \\ 43600 UKM Bangi, Selangor, Darul Ehsan, Malaysia
}

Received 6 Dec 2011; accepted 2 Feb 2012

\begin{abstract}
The study is concerned with normal-strength concrete corbels. 30 such corbels were studied by finite element modelling and the variables considered include ratios of primary and secondary reinforcement, type of applied loading, vertical or horizontal. Finite element modelling with a software package LUSAS was used to analyse four series of corbels namely PV series (primary reinforcement with vertical loading), SV series (secondary reinforcement with vertical loading), PH series (primary reinforcement with horizontal loading) and SH series (secondary reinforcement with horizontal loading). The results indicate that corbels with neither primary reinforcement nor secondary reinforcement fail suddenly. In the case of PV series and SV series, corbels increase in ratio of primary and secondary reinforcement generally resulted in enhancement of strength and ductility when subjected to only vertical loading. This increase is significant up to $0.4 \%$ in the case of primary reinforcement and $0.3 \%$ in the case of secondary reinforcements. No noticeable change in ultimate load or ductility was observed for corbels in PH series and SH series.
\end{abstract}

Keywords: connection; corbel; primary reinforcement; secondary reinforcement.

Reference to this paper should be made as follows: Rezaei, M.; Osman, S. A.; Shanmugam, N. E. 2013. Primary and secondary reinforcements in reinforced concrete corbels, Journal of Civil Engineering and Management 19(6): 836-845. http://dx.doi.org/10.3846/13923730.2013.801896

\section{Introduction}

A report on the 1964 Alaskan earthquake indicated that a substantial number of precast concrete structures distressed as a result of insufficient attention to their connections (Clottey 1977). Connections in precast concrete construction, particularly of primary members, form a critical part of the load-carrying and transfer mechanism. Most of the simple precast concrete connections are assembled with corbels, used extensively for beamcolumn connections. Corbels are projections from faces of columns and they behave like short cantilevered deep beams. Because of the usually low shear span-to-effective depth ratio the loads are transferred predominantly through shear. The principal parameters influencing the structural response of reinforced concrete corbels are type (monotonic or cyclic) and direction (vertical or horizontal) of external loads, shear span-to-depth ratio, strength of concrete, shape and dimensions of corbels, grade and arrangements of longitudinal and transverse steel reinforcements (Kriz, Raths 1965; Mattock et al. 1976; Yong, Balaguru 1994; Fattuhi 1994). Depending on the combination of these parameters, the ultimate loads and failure mode can change; in the worst case shear brittle failure (diagonal splitting) occurs, while in the best case ductile flexural failure mode is observed. Provision of secondary reinforcements reduces crack widths, improves ductility, changes failure mode from diagonal splitting to ductile (Fattuhi 1995).

Two types of reinforcement - primary and secondary are designed in order to avoid the sudden failure of a plain concrete corbel. Primary reinforcements are mostly attributed to the cause of ductile failure and secondary reinforcements are accentuated when either combination of vertical and horizontal loading or dynamic loading is involved. Secondary reinforcements are normally used to improve the shear capacity and reduce the likelihood of sudden failure. However, the contribution of secondary reinforcements has been shown to be variable when corbels are subjected either to combined vertical and horizontal loading or dynamic loading. Furthermore, most corbels without secondary reinforcement fail in shear that displays little or no ductility (Fattuhi 1995). Therefore, it is expected that the ratios of primary and secondary reinforcements influence the ultimate load carrying-capacity of corbels.

Kriz and Raths (1965) carried out 195 tests on corbels of which 121 were subjected to vertical loads, and 71 to combined vertical and horizontal loads. The variables included in the tests were: size and shape of the corbel, amount of primary reinforcement, concrete 
strength, ratio of shear span-to-effective depth and ratio of horizontal force to the vertical force. They proposed an empirical formula to calculate the vertical load at ultimate capacity of the corbel. Mast (1965) introduced the shearfriction concept to the design of corbels. Mast's (1965) objective was to develop a simple rational approach based on a physical model, which could be used to design a number of different types of concrete connections. The approach assumes a number of possible failure planes and then such reinforcement is chosen that failure along these planes is prevented. Mast (1965) applied his design method to the test data reported by Kriz and Raths (1965). He considered only those specimens having shear span-to-effective depth $(a / b)$ of less than 0.7 , and where the steel has yielded. Tests showed that the shear-friction hypothesis gives a good strength prediction for both vertical loading only and combined vertical and horizontal loading. Mattock (1976) tested 28 reinforced concrete corbels subjected to vertical and horizontal loads. The variables included: the ratio of shear span-to-effective depth, the ratio of vertical load to horizontal load, the amount of steel reinforcements, the concrete strength and the type of aggregate. They also developed an empirical expression for the strength of corbels without stirrups. They concluded that the minimum amount of stirrups should always be provided.

The PCI Design Handbook (2004) is basically based on Mattock's design method, modified slightly in capacity reduction factor. The strut-and-tie method is considered as a basic tool for analysis and design of reinforced concrete structures and has been incorporated in different codes of practice. The stress trajectories or load path methods are used to generate strut-and-tie models. However, the models produced by these methods are not unique. Tests of 28 deep beams were carried out by Zielinski and Rigotti (1995) in order to define the maximum carrying capacity and rational reinforcement ratio for structures such as deep beam, corbels and dapped-end beam. Strutand-tie method was used to analyse the test results. They proposed that the maximum usable amount of reinforcement can be obtained by $\rho=0.424 f_{\mathrm{c}}^{\prime} / f_{\mathrm{y}}$ for beams reinforced by horizontal reinforcement and by $\rho=0.85 f_{\mathrm{c}}^{\prime} / f_{\mathrm{y}}$ for beams reinforced by inclined reinforcement. Hwang et al. (2000) proposed a softened strut-and-tie model for determining the shear strength of corbels associated with failure of the compression strut. The precision of the analytical model was gauged by some experimental results from previous researchers. A new model for determining the shear strength of reinforced concrete corbels or brackets was proposed by Russo et al. (2006). The model was based on the equilibrium conditions of the strut-and-tie mechanism.

By adding artificial substances, e.g. fibre to plain concrete, the compressive and/or tensile strength of concrete would increase. Tests on corbels made of highstrength concrete and various secondary reinforcements such as monofilament polypropylene fibres, steel fibres and plastic mesh were carried out by many researchers (Fattuhi 1987, 1990; Yong et al. 1985; Abdul-Wahab 1989; Saafi, Toutanji 1997; Al-Shawi et al. 1999; Bourget et al. 2000; Ahmad, Shah 2008; Yousif 2008; Aziz,
Othman 2009). The test results have shown that corbels reinforced with steel fibres sustained smaller crack widths, achieved high strengths and failed in a gradual and controlled manner. Campione et al. (2005) examined, through experimental studies, the flexural behaviour of corbels made of plain or fibrous concrete with steel bars. They observed that the presence of a higher steel reinforcement may not allow the complete yielding of the primary reinforcement and it results in a brittle failure due to the crushing of the compressed regions.

Campione (2009a) proposed a strut-and-tie macromodel to determine the flexural response of fibre reinforced concrete (FRC) corbels, reinforced with longitudinal bars and subjected to vertical load. The simplified flexural response of corbels was in good agreement with experimental results reported by other researchers. The model was extended by Campione (2009b) to predict the flexural behaviour of corbels made of plain and fibrous concrete. The main focus of his study was to determine the loaddeflection curves of corbels subjected to both vertical and horizontal loads.

Due to the fact that corbels may need to get repaid after constructing, a bridge corbel was strengthened by steel plates (Bi-hai et al. 2009). The results showed that it is feasible to strengthen corbels with vertical-bounded steel plates. The possibility of using CFRP (Carbon Fiber Reinforced Polymers) laminates to strengthen corbels was studied (Ahmad et al. 2010). The behaviour of highstrength steel fibre reinforced concrete corbels (HSSFRC) was studied by Abdul-Razzak and Mohammed Ali (2011a). They proposed new material constitutive relationships by means of a regression analysis of experimental data, which were employed to formulate the material finite element (FE) models. Later, more sophisticated FE models for reinforced concrete corbels were developed (Abdul-Razzak, Mohammed Ali 2011b; Syroka et al. 2011).

Artificial neural network may be interested to analytical codes to predict the outputs as a function of input parameters after training according to the experimental or numerical data. An artificial network model was developed to measure the ultimate shear strength of steel fibrous reinforced concrete corbels (SFRC) without shear reinforcement (Kumar, Barai 2010). The models give satisfactory predictions of the ultimate shear strength when compared with available test results and some existing models. In addition, a parametric study was carried out. The effect of the primary reinforcement in the SFRC corbels was the most sensitive and a slight increase of primary reinforcement up to $1.3 \%$ was observed, which is significant in the shear capacity of corbels. The shear strength was almost constant beyond $1.3 \%$.

In accordance with ACI 318-05 (2008), the crosssectional area of secondary reinforcement shall not be less than $0.04\left(f_{\mathrm{c}}^{\prime} / f_{\mathrm{y}}\right)$. A similar requirement is also given by the PCI (Precast/Prestressed Concrete Institute). Despite the number of studies carried out on corbels only a few of them have addressed the issues of varying the ratios of primary or secondary reinforcements. This paper is, therefore, concerned with corbels in which ratios of primary or secondary reinforcements are varied. Sixteen 
reinforced concrete corbels were designed in accordance with the PCI. These corbels were analysed under vertical or horizontal loading using the FE modelling with the software package LUSAS (2006). Since no limit to ratios of primary and secondary reinforcements is found, this paper aims at determining, based on the results, optimal ratios that could establish some guidelines on the provision of reinforcements.

\section{FE analysis of corbels}

\subsection{Modelling}

With the development of high-powered computers, together with state-of-the-art FE software and user-friendly graphical interfaces, three-dimensional (3-D) FE analysis has become a popular choice to predict the behaviour of structural elements. FE software LUSAS version 14.1 (2006) has been used in this study. Steel is assumed to behave as an elastic-perfectly plastic material in both tension and compression. The idealised stress-strain curve used in the numerical analysis is shown in Figure 1. The material properties of steel were specified using the elastic and the metal plasticity with plastic options. LUSAS requires input of the Young's modulus, E, Poisson's ratio, $v$, and yield stress of steel, $\sigma_{\mathrm{y}}$.

Solid elements in LUSAS library are capable of predicting the non-linear behaviour concrete. The element characteristic is able to describe elastic, isotropic, plastic and multi-crack concrete behaviour. Concrete is a quasibrittle material and has different behaviour in compression and tension. The multi-crack concrete with crushing material model is based on a multi-surface plasticity approach to represent the non-linear behaviour of concrete in both tension and compression. The model simulates directional softening and crushing in compression using the same yield functions. Cracks in tension are assumed to form when the major principal stress reaches the tensile strength, after which a permanent crack plane is formed. Multiple cracks can form at non-orthogonal directions to one another. The model simulates non-linear behaviour in compression with hardening and softening functions applied to the local yield surfaces. In tension zones

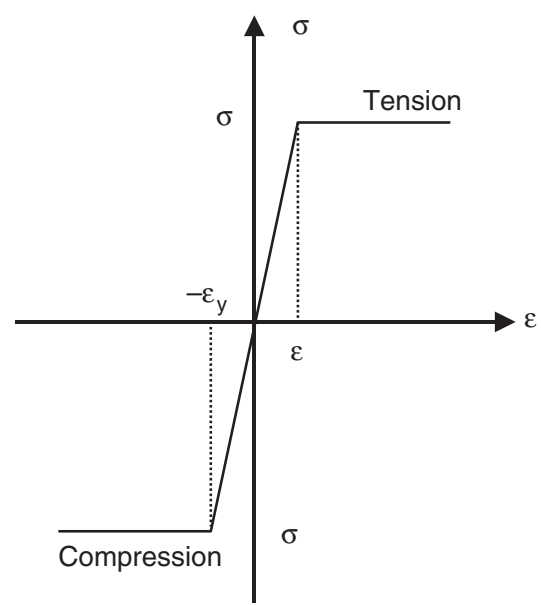

Fig 1. Stress-strain curve for steel permanent crack planes result in directional loss of strength, whereas in compression zones the planes are not permanent but rather may rotate and result in an isotropic loss of strength. In both tension and compression unloading from the yield surface is assumed to be elastic.

The tensile strength of concrete is typically $8-15 \%$ of the compressive strength; stress-strain relationship for concrete assumed in the analyses is shown in Figure 2.

It is necessary to assess the accuracy of the proposed FE modelling so that the modelling could be used for the analyses of corbels considered in the present study. Seven specimens tested by Foster et al. (1996) were considered in this study to assess the accuracy of the modelling by LUSAS. All specimens were modelled and analysed with LUSAS and the results presented in Figure 3. It is clear from the figure that FE results are close to the corresponding experimental values, maximum deviation being $15 \%$. The difference could be attributed to the assumptions used for the modelling in which the properties of some of the materials and dimensions not given in the paper were assumed. Since LUSAS has been found to predict results with acceptable accuracy the software package was used for further analyses.

\subsection{Analyses}

The dimensions along with the loading applied on corbels, typical of those examined, are shown in Figure 4.

The corbel cantilevering on either side of the column was $254 \times 305 \mathrm{~mm}$ in cross section and $965 \mathrm{~mm}$ long. The column was reinforced with four 16-mm-diameter longitudinal bars and 9-mm-diameter stirrups spaced at $216 \mathrm{~mm}$ centre to centre as shown in the figure. The reinforcement details for all the corbels analysed herein are listed in Table 1.

Each of the corbels is identified in the text by designation such as PV-0.15 and PH-0.15. In the designation of the specimens, $\mathrm{P}$ refers to corbels associated with primary reinforcement, $\mathrm{S}$, corbels associated with secondary reinforcement, $\mathrm{V}$, corbels subjected only to vertical loading, and $\mathrm{H}$, corbels subjected only to horizontal loading. For example, PH- 0.15 refers to the corbel

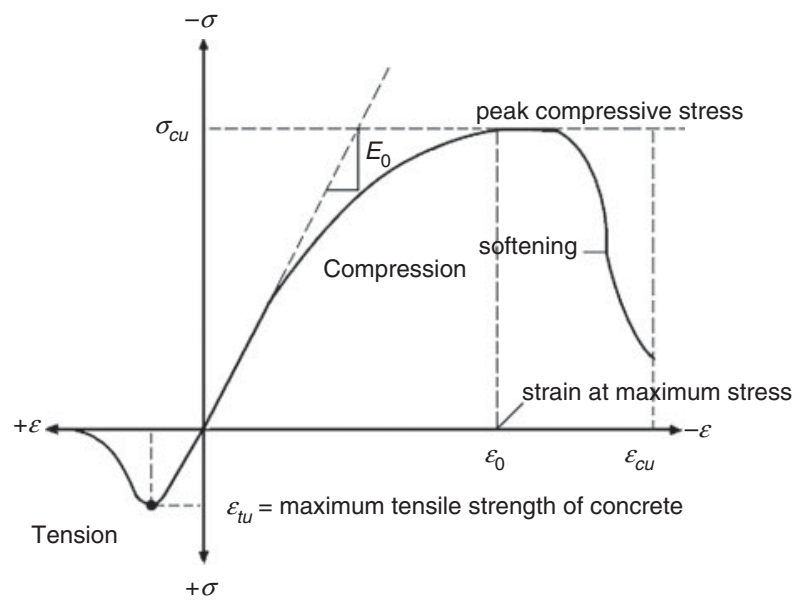

Fig. 2. Stress-strain curve of concrete 


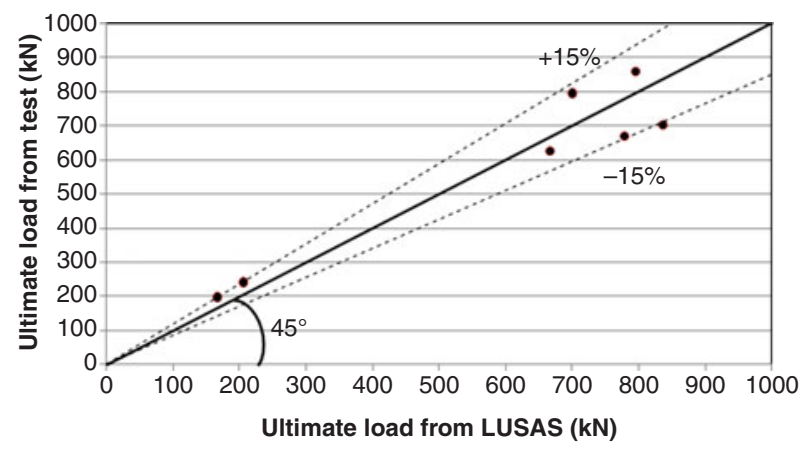

Fig. 3. Comparison between FE results and test results

in Series $\mathrm{P}$ with $0.15 \%$ primary reinforcement (crosssectional area of primary reinforcement over cross section of the corbel), and also subjected only to horizontal loading. Also, four corbels without either primary or secondary reinforcements were analysed. In Series PV and $\mathrm{PH}$, the cross-sectional area of primary reinforcement was varied from 0 to $565.8 \mathrm{~mm}^{2}$, and the area of secondary reinforcement kept constant. On the other hand, in Series $\mathrm{SV}$ and $\mathrm{SH}$, the steel area of primary reinforcement was kept constant while the area of secondary reinforcement varied from 0 to $257.2 \mathrm{~mm}^{2}$. For all models, the material properties such as Young's modulus of $26 \times 10^{3}$ and $209 \times 10^{3} \mathrm{~N} / \mathrm{mm}^{2}$, Poisson's ratio, 0.2 and 0.3 for concrete and steel, respectively were kept the same. The compressive strength of concrete and the yield stress of steel were assumed $30 \mathrm{MPa}$ and $420 \mathrm{MPa}$, respectively.

In the analyses of all models, top and bottom of the column were assumed fixed and the load applied incrementally on a bearing pad made of steel as shown in Figure 4. Thickness of the bearing pad of $15 \mathrm{~mm}$ was so chosen that crushing of the concrete was prevented effectively. In the analyses, corbels were subjected either to vertical or horizontal loading as shown in Figure 4. The loadings are representative of beam reactions in the vertical direction and, horizontal force due to surge in the case of dynamic loading. Except the ratio of primary to secondary reinforcements and direction of applied load, details of all the models were kept the same. Taking advantage of the symmetry in geometry, loading and support conditions only a quarter of the models was analysed in order to reduce the computational time. Mesh size of $30 \times 30 \mathrm{~mm}$ was chosen based on convergence studies carried out to determine the optimal mesh that gives a relatively accurate solution and one that takes low computational time. In LUSAS, to set the incremental loading (automatic or manual) for a non-linear analysis,

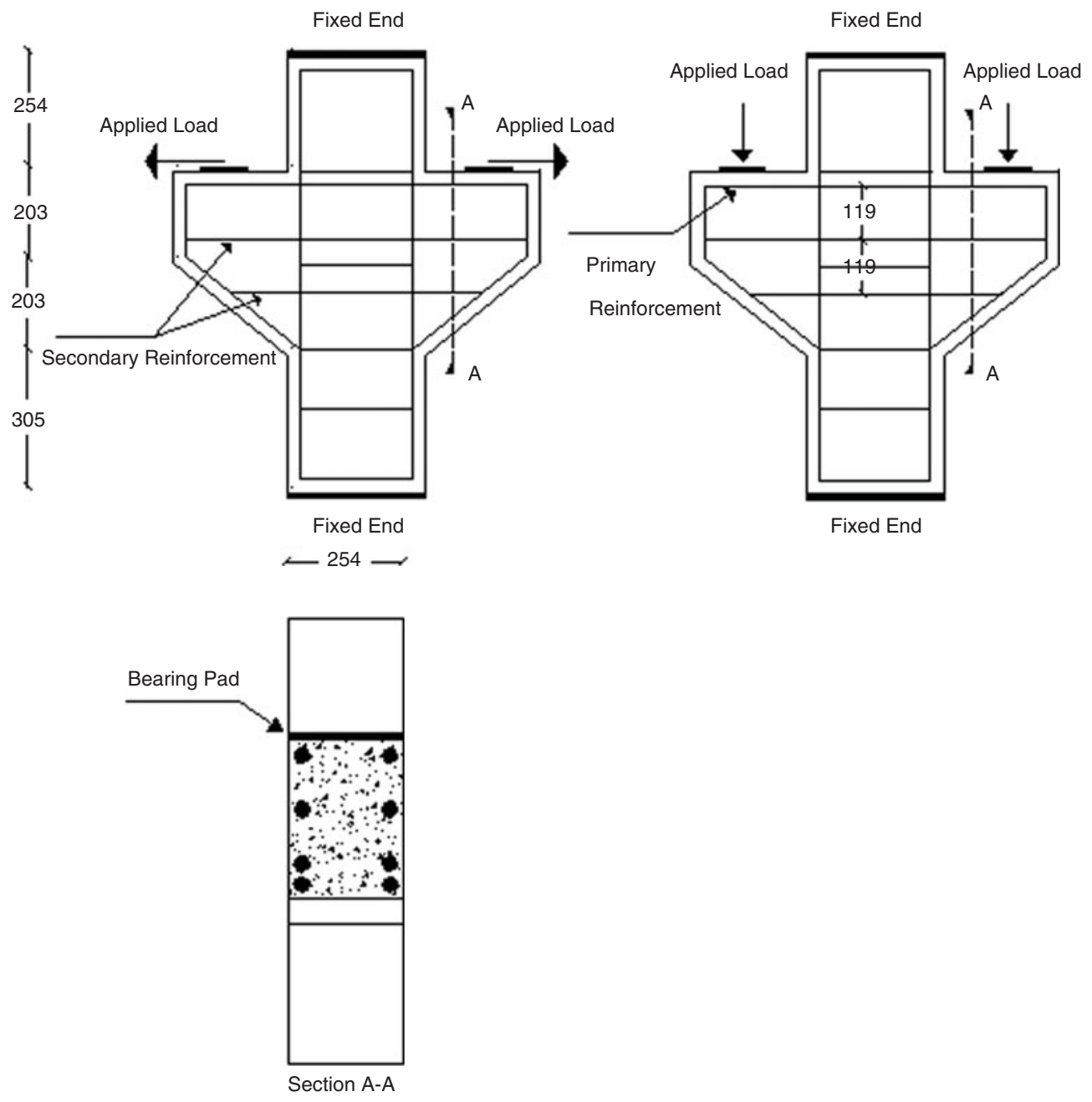

Fig. 4. Reinforcement detailing (dimensions in $\mathrm{mm}$ ) 
Table 1. Details of reinforcements in the corbels

\begin{tabular}{l|c|c}
\hline Designation & $\begin{array}{c}\text { Secondary } \\
\text { reinforcement } \\
\left(\mathrm{mm}^{2}\right)\end{array}$ & $\begin{array}{c}\text { Primary } \\
\text { reinforcement } \\
\left(\mathrm{mm}^{2}\right)\end{array}$ \\
\hline PV-0.0, PH-0.0 & 127.2 & 0.0 \\
\hline PV-0.15, PH-0.15 & 127.2 & 154.3 \\
\hline PV-0.20, PH-0.20 & 127.2 & 205.7 \\
\hline PV-0.30, PH-0.30 & 127.2 & 308.6 \\
\hline PV-0.35, PH-0.35 & 127.2 & 360.0 \\
\hline PV-0.40, PH-0.40 & 127.2 & 411.5 \\
\hline PV-0.45, PH-0.45 & 127.2 & 462.9 \\
\hline PV-0.50, PH-0.50 & 127.2 & 514.4 \\
\hline PV-0.55, PH-0.55 & 127.2 & 565.8 \\
\hline SV-0.0, SH-0.0 & 0.0 & 265.2 \\
\hline SV-0.15, SH-0.15 & 77.2 & 265.2 \\
\hline SV-0.20, SH-0.20 & 102.9 & 265.2 \\
\hline SV-0.30, SH-0.30 & 154.3 & 265.2 \\
\hline SV-0.40, SH-0.40 & 205.7 & 265.2 \\
\hline SV-0.45, SH-0.45 & 231.5 & 265.2 \\
\hline
\end{tabular}

specifies how an automatic solution is to proceed and when it should terminate. There are two ways to apply load, named attained load and control displacement. The attained load usually takes more time, therefore, control displacement was used in this study. A typical FE model is shown in Figure 5.

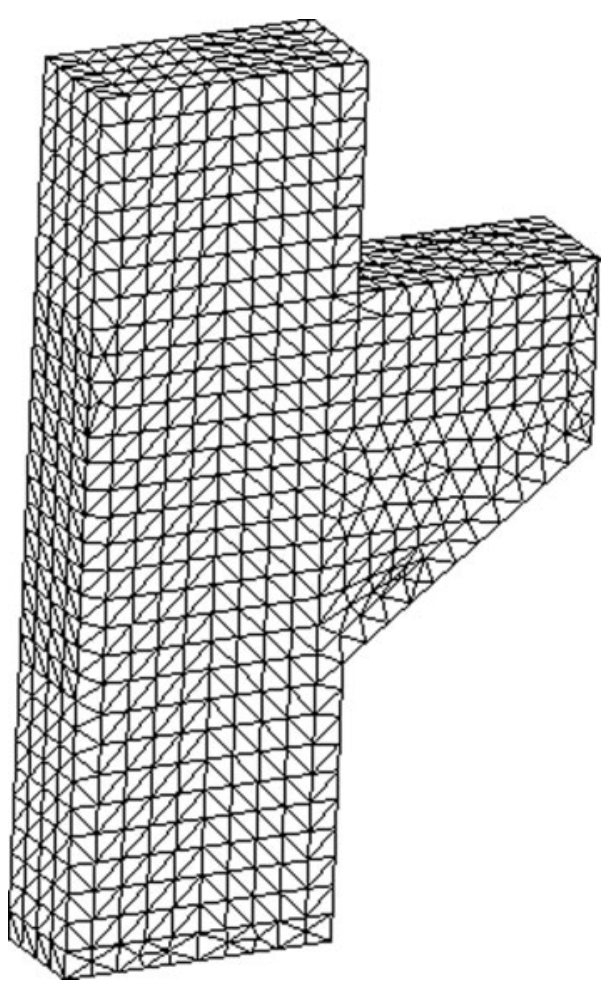

Fig. 5. FE model for a quarter of a corbel

\section{Results and discussion}

Analysis was carried out on each of the models until failure of the specimen was achieved. Extensive results for each of the models were obtained in the form of loaddeflection plots. However, selected results are presented as shown in Figures 6-9. Displacements under the applied load are plotted on the horizontal axis and the corresponding load on the vertical axis. Discussion of these results are presented in the following sections.

\subsection{Results for PV series}

The results obtained for the PV series models are summarised in Table 2 and the corresponding loaddeflection plots shown in Figure 6. Only the ratio of cross section in respect of primary reinforcement was varied in this series. Addition of primary reinforcement to corbels appears to have enhanced the ductility and toughness with the degree of enhancement evident in corbels reinforced with a lower ratio of primary reinforcement. It can be seen from Table 2 that ultimate shear capacity increases significantly with increase in the ratio of primary reinforcement.

However, this increase is sustainable only up to the reinforcement ratio of $0.4 \%$, beyond which the increase in ultimate load is marginal. For example, the ultimate shear values for the corbel PV-0.2 and PV- 0.4 are $667 \mathrm{kN}$ and $930 \mathrm{kN}$, respectively; compared to the corresponding value in respect of PV-0.0, increase by $145 \%$ and $242 \%$ for $0.2 \%$ and $0.4 \%$ primary reinforcement ratios, respectively. The corbel PV-0.5, however, could carry until failure, only at $970 \mathrm{kN}$, a very small increase if compared to PV-0.4. The results show that any further increase in reinforcement beyond $0.4 \%$ does not yield any improvement in the load resistance characteristics. The corbel PV-0 failed catastrophically in a brittle manner as expected. It can be seen from Figure 6 that the curves had either two or three segments. The first segment terminated at the occurrence of the first crack after which the strains increased rapidly even for a small load increment. The crack starts from the inner edge of the bearing pad and runs into corbel-column face diagonally. The strain of reinforcement bars is usually measured in order to find out whether the steel yields or not. This is followed quickly by the initiation of the second (primary) crack, the load-strain response becomes relatively linear until approximately $90 \%$ of the ultimate load. The first

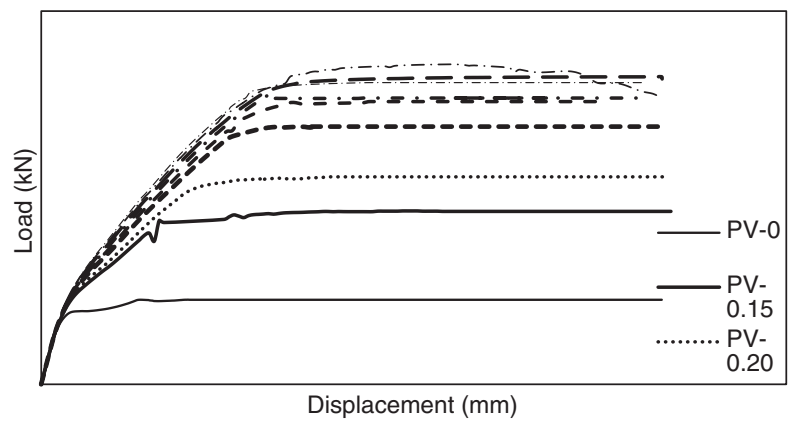

Fig. 6. Load-deflection curves series PV 


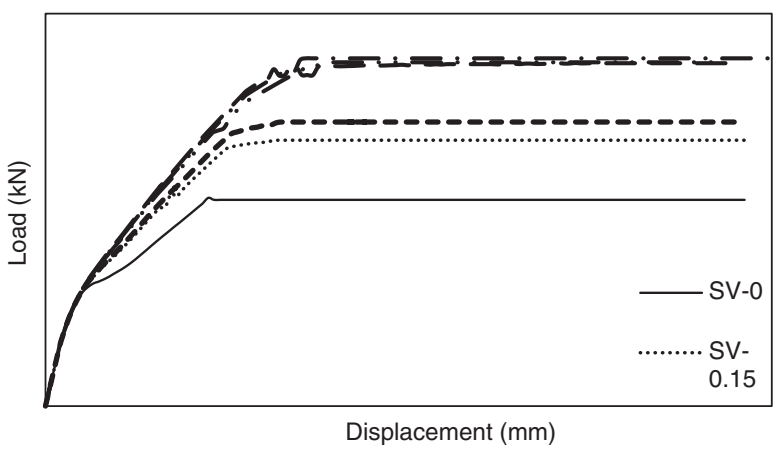

Fig. 7. Load-deflection curves series SV

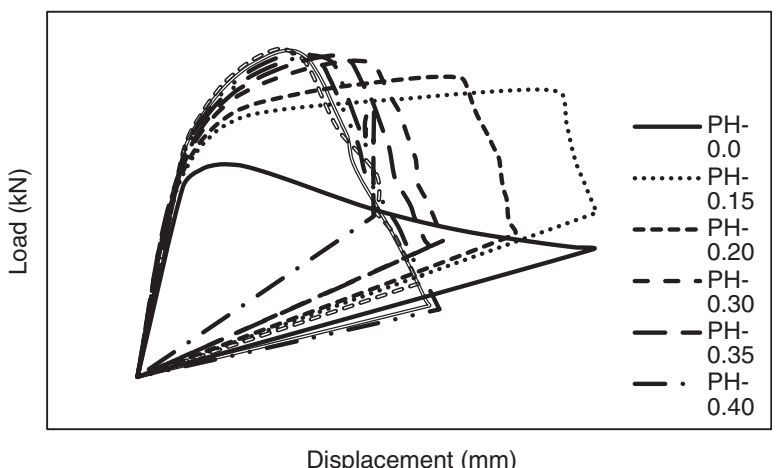

Fig. 8. Load-deflection curves series PH

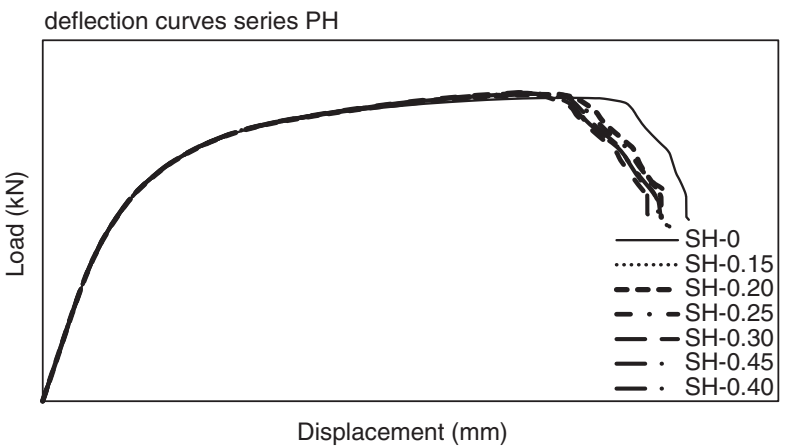

Fig. 9. Load-deflection curves series PH

Table 2. Corbel series PV

\begin{tabular}{l|c|c|c}
\hline Designation & $\begin{array}{c}\text { Ultimate shear } \\
\text { load }(\mathrm{kN})\end{array}$ & $\begin{array}{c}\text { Percentage } \\
\text { increase of } \\
\text { ultimate load }\end{array}$ & $\begin{array}{c}\text { Deflection at } \\
\text { ultimate } \\
\text { load }(\mathrm{mm})\end{array}$ \\
\hline PV-0.0 & 272 & 0 & 0.42 \\
\hline PV-0.15 & 557 & 105 & 0.45 \\
\hline PV-0.20 & 667 & 145 & 0.89 \\
\hline PV-0.30 & 736 & 171 & 0.94 \\
\hline PV-0.35 & 829 & 205 & 1.01 \\
\hline PV-0.40 & 930 & 242 & 0.91 \\
\hline PV-0.45 & 989 & 264 & 1.09 \\
\hline PV-0.50 & 970 & 257 & 1.28 \\
\hline PV-0.55 & 1029 & 278 & 1.66 \\
\hline
\end{tabular}

segment of the curves is steep followed by a kink and rapid increase of crack width coincident with the formation of the primary crack.

\subsection{Results for SV series}

In this series, the cross-sectional area of secondary reinforcement varies from $0.0 \%$ to $0.45 \%$ and the models are analysed under the action of vertical loadings. The load is increased until failure with the behaviour of the corbels and their deflection recorded at selected interval of loading. Results thus obtained from the analyses are summarised in Table 3 and the load-deflection curves for the models are shown in Figure 7.

It is noted from the analyses that in all models flexural cracks that start at or near the junction of the tension face of the corbel and face of the column appeared first. The results show clearly that presence of additional secondary reinforcement resulted in an increase in loadcarrying capacity as well as in ductility of corbels. Corbels SV-0.0 containing no secondary reinforcement failed suddenly in an explosive manner. Increase in loadcarrying capacity of corbels is found to be significant for corbels with the percentage of secondary reinforcement up to $0.3 \%$. For example, as shown in Table 3, the ultimate shear values for SV-0.0 and SV-0.3 are $530 \mathrm{kN}$ and 770 $\mathrm{kN}$, respectively, which is an increase of $45 \%$. This increase in ultimate shear becomes gradually insignificant for the ratio of secondary reinforcement beyond 0.3 . The load deflection curves, as shown in Figure 7, are similar to those shown for PV series with stages of almost linear behaviour. The load-deflection plots for corbels with reinforcement ratios $0.3 \%$ and above lie very close to each other, indicating that the influence of reinforcement ratio beyond $0.3 \%$ on ultimate shear capacity is negligible.

\subsection{Results for $\mathrm{PH}$ series}

Nine corbels, in which the ratio of primary reinforcement varied from $0.0 \%$ to $0.55 \%$, were analysed under horizontal loading in this series. The analyses of the models in this series were similar to those in series PV, except the loading, which was horizontal in this case. The results obtained from the analyses are presented in the form of

Table 3. Corbel series SV

\begin{tabular}{l|c|c|c}
\hline & Ultimate shear & $\begin{array}{c}\text { Percentage } \\
\text { increase in } \\
\text { ultimate } \\
\text { load }(\%)\end{array}$ & $\begin{array}{c}\text { Deflection at } \\
\text { ultimate } \\
\text { load }(\mathrm{mm})\end{array}$ \\
\hline SV-0 & 530 & 0 & 0.58 \\
\hline SV-0.15 & 677 & 28 & 0.83 \\
\hline SV-0.20 & 724 & 36 & 0.85 \\
\hline SV-0.30 & 770 & 45 & 0.95 \\
\hline SV-0.40 & 876 & 65 & 0.99 \\
\hline SV-0.45 & 886 & 67 & 0.93 \\
\hline
\end{tabular}


Table 4. Corbel series PH

\begin{tabular}{l|c|c|c}
\hline Designation & $\begin{array}{c}\text { Ultimate shear } \\
\text { load (kN) }\end{array}$ & $\begin{array}{c}\text { Percentage } \\
\text { increase of } \\
\text { ultimate } \\
\text { load }(\%)\end{array}$ & $\begin{array}{c}\text { Deflection at } \\
\text { ultimate } \\
\text { load (mm) }\end{array}$ \\
\hline PH-0 & 82 & 0 & 0.04 \\
\hline PH-0.15 & 110 & 35 & 0.22 \\
\hline PH-0.20 & 115 & 41 & 0.16 \\
\hline PH-0.30 & 121 & 49 & 0.13 \\
\hline PH-0.35 & 123 & 51 & 0.11 \\
\hline PH-0.40 & 123 & 51 & 0.1 \\
\hline PH-0.45 & 124 & 52 & 0.09 \\
\hline PH-0.50 & 125 & 53 & 0.09 \\
\hline PH-0.55 & 125 & 54 & 0.08 \\
\hline
\end{tabular}

load-deflection plots as shown in Figure 8 and summary of results given in Table 4.

It can be seen from the figure and the table that the corbel PH- 0.0 failed at the lowest load; this is expected since no primary reinforcement was provided in the corbel. The load-deflection plot in respect of the corbel PH- 0.0 does not show brittle behaviour as observed in the corbel PV-0.0. The shape and area beneath the load deflection curves are often used as indicators of ductility and toughness, respectively. It can be seen from the figure that the corbels with primary reinforcement ratio of $0.3 \%$ and above display similar behaviour, almost the same value of ultimate shear capacity and the same ductility. An increase in horizontal load due to an increase in primary reinforcement ratio is, however, not appreciable.

\subsection{Results for SH series}

In this series consisting of eight corbels with secondary reinforcement ratio varied from $0.0 \%$ to $0.5 \%$ were analysed under horizontal loading only. The results obtained from the analyses are given in Figure 9 in the form of load-deflection curves and summarised in Table 5. The figure shows that the curves for all models coincide

Table 5. Corbel series PH test results

\begin{tabular}{l|c|c|c}
\hline Designation & $\begin{array}{c}\text { Ultimate shear } \\
\text { load (kN) }\end{array}$ & $\begin{array}{c}\text { Percentage } \\
\text { increase of } \\
\text { ultimate } \\
\text { load (\%) }\end{array}$ & $\begin{array}{c}\text { Deflection at } \\
\text { ultimate } \\
\text { load (mm) }\end{array}$ \\
\hline SH-0 & 118 & 0 & 0.14 \\
\hline SH-0.15 & 118 & 0.2 & 0.14 \\
\hline SH-0.20 & 119 & 1.1 & 0.14 \\
\hline SH-0.30 & 119 & 1.2 & 0.14 \\
\hline SH-0.35 & 119 & 1.3 & 0.14 \\
\hline SH-0.40 & 119 & 1.4 & 0.14 \\
\hline SH-0.45 & 119 & 1.4 & 0.14 \\
\hline SH-0.50 & 120 & 1.5 & 0.15 \\
\hline
\end{tabular}

indicating that the variation in reinforcement ratio does not affect the behaviour in any respect. The results in the figure and in the table clearly show that the effect of increase in reinforcement ratio has insignificant effect on the ultimate shear load.

\section{Evaluation of PCI equation}

The PCI recommends equations based on friction theory for reinforced concrete corbels. According to PCI, a corbel is theoretically capable of carrying loads of any magnitude. In accordance with the PCI, $A_{\mathrm{s}}$, cross-sectional area of primary reinforcement is taken as the larger of the two values given by Eqns (1) and (2):

$$
\begin{gathered}
A_{\mathrm{s}}=1 / \phi f_{\mathrm{y}}\left[v_{\mathrm{u}}\left(\frac{a}{b}\right)+N_{\mathrm{u}}\left(\frac{h}{d}\right)\right] ; \\
A_{\mathrm{s}}=\frac{1}{\phi f_{\mathrm{y}}}\left[\frac{2 V_{\mathrm{u}}}{3 \mu_{\mathrm{e}}}+N_{\mathrm{u}}\right],
\end{gathered}
$$

in which: $a$ is the eccentricity of applied load; $d$-depth of primary reinforcement; $h$ - height of corbel; $\mu_{\mathrm{e}}$ - effective shear-friction coefficient as defined in section 11.7.3 of ACI 318-05 (2008); $\phi$ - strength reduction factor equal to $0.75, f_{\mathrm{y}}$ - yield strength of tension steel; $V_{\mathrm{u}}$ - factored vertical load applied and $N_{\mathrm{u}}$ - factored horizontal load applied.

The minimum primary steel required in tension is given as:

$$
A_{s, \min }=0.04 \frac{f_{\mathrm{c}}^{\prime}}{f_{\mathrm{y}}} b d
$$

where: $b$ is width of corbel and $f_{\mathrm{c}}-$ concrete strength in compression.

The required cross-sectional area of the secondary reinforcement is calculated as:

$$
A_{\mathrm{n}}=\frac{N_{\mathrm{u}}}{\phi f_{\mathrm{y}}} ;
$$

$$
A_{\mathrm{h}} \geq 0.5\left(A_{\mathrm{s}}-A_{\mathrm{n}}\right)
$$

in which: $A_{\mathrm{h}}$ is cross-sectional area of secondary reinforcement, distributed within the upper $2 / 3$ of the corbel depth. In order to evaluate the above equations, a number of corbels were designed using the PCI equations. The resulting reinforcement ratios, primary or secondary and the corresponding horizontal or vertical loading are listed in Table 6 .

All the dimensions and material strengths were kept the same as those corbels analysed using the FE method in the current studies. It can be seen from the table that primary reinforcements have significant influence on the behaviour of corbels. It could change the mode of failure from catastrophic to flexure, in which reinforcements 
Table 6. Details of reinforcements in corbels designed as per PCI equations

\begin{tabular}{l|c|c|c|c}
\hline Corbel designation & Vertical loading $(\mathrm{kN})$ & Horizontal loading $(\mathrm{kN})$ & $\begin{array}{c}\text { Ratio of primary } \\
\text { reinforcement (\%) }\end{array}$ & $\begin{array}{c}\text { Ratio of secondary } \\
\text { reinforcement }(\%)\end{array}$ \\
\hline 1 & 700 & 0 & 0.4 & 0.2 \\
\hline 2 & 800 & 0 & 0.46 & 0.23 \\
\hline 3 & 900 & 0 & 0.52 & 0.26 \\
\hline 5 & 1000 & 0 & 0.58 & 0.29 \\
\hline 6 & 1100 & 0 & 0.63 & 0.32 \\
\hline 7 & 1200 & 0 & 0.69 & 0.35 \\
\hline 9 & 1300 & 0 & 0.75 & 0.37 \\
\hline 10 & 1400 & 0 & 0.26 & 0.4 \\
\hline 11 & 0 & 100 & 0.27 & 0.06 \\
\hline 13 & 0 & 160 & 0.37 & 0.01 \\
\hline 14 & 0 & 220 & 0.47 & 0.01 \\
\hline 15 & 0 & 280 & 0.57 & 0.02 \\
\hline
\end{tabular}

yield before concrete crushes. The results presented for the corbels in PV series and SV series showed significant difference in behaviour due to different reinforcement ratios that would lead to change the failure mode. The change in ductility is more apparent in the case of PV Series. Concrete corbels containing neither primary nor secondary reinforcement failed in brittle manner with a noticeable difference in ultimate load. Results from the $\mathrm{PH}$ and SH series showed that the presence of primary or secondary reinforcements did not enhance significantly either the ductility or the load-carrying capacity.

It is clear from the results given in Table 6 that the primary and secondary reinforcement ratios increase as only the vertical load is increased. Similar observations could be made when only the horizontal load is increased but, with moderate increase in the secondary reinforcement ratio. It was shown earlier in the case of PV series that the increase in ratio of primary reinforcement beyond $0.4 \%$ does not affect the load-carrying capacity. Also, it was noted in series SV that an increase in the secondary reinforcement ratio of up to 0.3 enhances the loadcarrying capacity of corbels and has no significant effect thereafter. But the PCI does not provide any limitation on the reinforcement ratio, primary or secondary. In accordance with the PCI equations, both primary and secondary reinforcement ratios increase notably when the corbel was subjected only to vertical loading. When a corbel was subjected only to horizontal loading, on the other hand, the primary reinforcement ratio increased significantly; the corresponding increase in the secondary reinforcement ratio is not as significant as that of the primary ratio. It should be noted that this study was made for only width/ height, $a / d$, ratio of corbels equal to 0.64 , and hence it is necessary to carry out further studies covering a wider range of parameters.

\section{Conclusions}

The following conclusions can be drawn based on the results:

1) The failure mode of corbels with neither secondary reinforcement nor primary reinforcement was brittle and explosive when corbel was subjected to only vertical loading;

2) The ultimate load of a corbel was increased by increase in percentage of primary reinforcement steel, nevertheless, it is mostly pronounced for lower ratios of the main reinforcement;

3) The load-carrying capacities of corbels are considerably enhanced by the addition of secondary reinforcements when a corbel was subjected to only vertical loading. The enhancement is noticeable until the percentage of secondary reinforcement reached to $0.3 \%$;

4) The PCI equations do not specify any limits on the ratio of primary and secondary reinforcement. The study showed that some limits should be introduced in the code.

\section{References}

Abdul-Razzak, A. A.; Mohammed Ali, A. A. 2011a. Modelling and numerical simulation of high strength fibre reinforced concrete corbels, Applied Mathematical Modelling 35(6): 2901-2915. http://dx.doi.org/10.1016/j.apm.2010.11.073

Abdul-Razzak, A. A.; Mohammed Ali, A. A. 2011b. Influence of cracked concrete models on the nonlinear analysis of high strength steel fiber reinforced concrete corbels, 
Composite Structures 93(9): 2277-2287.

http://dx.doi.org/10.1016/j.compstruct.2011.03.016

Abdul-Wahab, H. M. S. 1989. Strength of reinforced concrete corbels with fibers, ACI Structural Journal 86(1): 60-66.

ACI 318-05. 2008. Shear and torsion. Part 11.8: provision for brackets and corbel. American Concrete Institute (ACI), Detroit. 188 p.

Ahmad, S.; Shah, A. 2008. Evaluation of shear strength of high strength concrete corbels using strut-and-tie model, The Arabian Journal for Science and Engineering 34: 27-35.

Ahmad, S.; Shah, A.; Nawaz, A.; Salimullah, K. 2010. Shear strengthening of corbels with carbon fiber reinforced polymers (CFRP), Materiales de Construccsion 60: 79-97. http://dx.doi.org/10.3989/mc.2010.50009

Al-Shawi, F. A. N.; Mangat, P. S.; Halabi, W. 1999. A simplified design approach to corbels made with high strength concrete, Materials and Structures 32: 579-583. http://dx.doi.org/10.1007/BF02480492

Aziz, O. Q.; Othman, Z. S. 2009. Ultimate shear strength of reinforced high-strength concrete corbels subjected to vertical loading, Al-Rafidain Engineering 18(1): 1-6.

Bi-hai, L.; Yuan-han, W.; Hong-Guang, C.; Yu, M. 2009. Reinforcement and numerical analysis on the corbel of a half-through arch bridge, Journal of Chongqing University 8(1): 57-62.

Bourget, M.; Delmas, Y.; Toutlemonde, F. 2000. Experimental study of the behaviour of reinforced high-strength concrete short corbel, Materials and Structures 34: 155-165. http://dx.doi.org/10.1617/13620

Campione, G. 2009a. Flexural response of FRC corbels, Cement \& Concrete Composites 31(3): 204-210. http://dx.doi.org/10.1016/j.cemconcomp.2009.01.006

Campione, G. 2009b. Performance of steel fibrous reinforced concrete corbels subjected to vertical and horizontal loads, Journal of Structural Engineering 135(5): 519-529. http://dx.doi.org/10.1061/(ASCE)0733-9445(2009)135:5 (519)

Campione, G.; Mendola, L. L.; Papia, M. 2005. Flexural behavior of concrete corbels containing steel fibers or wrapped with FRP sheets, Materials and Structures 38: 617-625. http://dx.doi.org/10.1617/14210

Clottey, C. 1977. Performance of lightweight concrete corbels subjected to static and repeated load: $\mathrm{PhD}$ Thesis. Oklahoma State University, Stillwater, OK.

Fattuhi, N. I. 1987. SFRC corbel tests, ACI Structural Journal 84(2): 119-123.

Fattuhi, N. I. 1990. Column-load effect on reinforced concrete corbels, Journal of Structural Engineering 116(1): 188-197.

http://dx.doi.org/10.1061/(ASCE)0733-9445(1990)116:1 (188)

Fattuhi, N. I. 1994. Strength of FRC corbels in flexure, Journal of Structural Engineering 120(2): 360-377. http://dx.doi.org/10.1061/(ASCE)0733-9445(1994)120:2 (360)

Mehdi REZAEI. A PhD candidate in UKM (the National University of Malaysia). He has obtained his Master's degree from UKM in 2008. He has published more than ten scientific papers in international journals and conference proceedings.

Siti Aminah OSMAN. Senior lecturer at the Department of Civil and Structural Engineering, the National University of Malaysia (UKM). She graduated from Universiti Teknologi Malaysia in 1992 with BEng(Hons), MSc in Structural Engineering from University of Bradford, UK (1995) and PhD in Civil and Structural Engineering from the UKM (2006). She is a member of the Board of Engineers Malaysia (BEM) and the Society of Engineering Education Malaysia (SEEM). After graduating from her undergraduate studies, she worked as a design engineer with Muhibbah Engineering for 6 months and then joined the UKM as a tutor. She has taught at undergraduate and graduate levels for more than 15 years. Her 
research interest includes structural engineering, wind engineering, structural dynamics and industrial building system (IBS) construction.

Nandivaram E. SHANMUGAM. A Professor at the Department of Civil and Structural Engineering, the National University of Malaysia (UKM). He obtained his PhD degree from the University of Wales (Cardiff) in 1978. He has taught at undergraduate and graduate levels for more than 45 years. He has published more than 200 scientific papers in international journals and conference proceedings. He is a member of the editorial board of the Journal of Constructional Steel Research, Thin-walled Structures, the Journal of Structural Stability and Dynamics, the International Journal of Steel Composite Structures, the International Journal of Steel Structures and the IES Journal Part A: Civil and Structural Engineering. He is a Chartered Engineer (CEng), Fellow of the Institution of Structural Engineers, London, (FIStructE), Fellow of the Royal Institution of Naval Architects (FRINA), Fellow of the American Society of Civil Engineers (FASCE), Fellow of the Institution of Engineers, Singapore (FIES) and Fellow of the Institution of Engineers, India (FIEI). His research interests include steel plated structures, steel-concrete composite construction, long-span structures and connections, cold-formed steel structures, elastic and ultimate load behaviour of steel structures, etc. 